\title{
DETECTING GLOBAL CHANGE IN THE ARCTIC
}

\author{
(Abstract) \\ by \\ Gunter Weller \\ (Geophysical Institute, University of Alaska Fairbanks, Fairbanks, AK 99775-0800, U.S.A.)
}

\begin{abstract}
Numerical models have predicted global temperature increases due to rising atmospheric $\mathrm{CO}_{2}$ levels, which should be detectable by now, but have not yet been identified in an unambiguous manner. This detection is complicated by inadequate data and by the fact that climate can be changed by factors other than $\mathrm{CO}_{2}$ increases. A systematic monitoring strategy is therefore needed to assess global change. In the Arctic, cryospheric parameters, including sea ice, snow cover, glaciers and permafrost are sensitive indicators of climate change and their monitoring by satellites and surface observations is of particular interest. Sea ice and snow cover are perhaps the most important of these parameters. They respond quickly to climate change, and in turn directly affect the climate through feedback processes; major changes in ice and snow extent and thickness can be expected as a consequence of climate change. Glaciers also respond to climatic variability by changes in their mass balance which can be monitored.
\end{abstract}

Melting glaciers raise the level of the world ocean, and the glaciers of the sub-Arctic, particularly in the Alaskan coastal mountains, have been major contributors to the observed sea-level rise of about $20-30 \mathrm{~cm}$ over the last century. Past temperature changes are recorded in glacier ice and permafrost and techniques are now available to reconstruct past climates from these sources.

The numerical models of the $\mathrm{CO}_{2}$ greenhouse effect show the polar regions to be affected most strongly by greenhouse warming, and sea ice, snow, glaciers and permafrost should be good indicators of such a global change. The known responses and sensitivities of cryospheric parameters to climate change are reviewed, and a monitoring strategy is suggested. The Alaska SAR Facility, utilizing synthetic aperture radar from several spacecraft scheduled for launch in the 1990s, will be a key facility for collecting and analyzing climate-related satellite data. Its monitoring capabilities are briefly reviewed.

\section{IMPURITY DISTRIBUTIONS IN ICE UNDER DIFFERENT ENVIRONMENTAL CONDITIONS}

\author{
(Abstract) \\ by \\ Eric Wolff and Robert Mulvaney \\ (British Antarctic Survey, Natural Environment Research Council, High Cross, \\ Madingley Road, Cambridge CB3 OET, UK)
}

We have shown previously (Mulvaney and others, 1988; Wolff and others, 1988) that some of the impurities in ice are localised. For samples from Dolleman Island in the Antarctic Peninsula, sulphuric acid was found at very high concentrations at the triple junctions (where three grains meet). No such localisation was found for sea salt elements, which are the other major soluble impurity. We believe that the acid is sufficiently concentrated at ice-sheet temperatures to remain liquid, forming a network of sub-micron veins through the ice.

We used a scanning electron microscope (SEM) fitted with an X-ray microanalysis system and a cold stage that holds samples below $-160^{\circ} \mathrm{C}$. Located at the University of Lancaster, the instrument allows frozen samples to be investigated with elemental analysis carried out at a resolution of the order of 1 micron.

Further experiments have yielded similar results for other samples from the same ice core. However, we have not yet found a method of cutting and cooling the samples that gives quantitatively reproducible data, so that it is too early to say what proportion of the acid in the sample is at the triple junctions.

Nonetheless, we have now also seen $\mathrm{S}$ at several triple junctions in ice from Site $G$ in central Greenland. The sample includes part of the material from the 1783 Laki volcanic eruption. We have still to look at samples from other sites, but are reassured that the positive result is not confined to one ice core.

This work, still at a formative stage, has posed some important questions:

(1) For us there is the technical question of how we obtain reproducible quantitative results.

(2) How widespread is the phenomenon, and how much of the acid is at triple junctions? This is the next phase of studies at Lancaster, and is likely to include a study of older ice, and of temperate ice.

(3) Why is the acid at triple junctions, and why is sea salt not found there? This must be due to processes in the atmosphere or snowpack, and is likely to be related to the eutectic temperatures of impurity/water mixtures. Thus the distribution may influenced by changes in climate or chemistry. For instance, Wisconsin-age ice in Greenland is neutral, any acid having reacted with alkali dusts. How did this affect the impurity distribution?

(4) If the distribution does change as a result of a changed environment, does this affect the physical properties of the ice itself? In particular, is the presence or absence of liquid at the junctions a contributory factor to the changes in rheology between Wisconsin and Holocene ice? We are far into the realms of speculation here, but this does have the potential to be an interesting long-timescale feedback to climatic and environmental changes.

\section{REFERENCES}

Mulvaney, R., E.W. Wolff, and K. Oates. 1988. Sulphuric acid at grain boundaries in Antarctic ice. Nature, 331, 247-249.

Wolff, E.W., R. Mulvaney, and K. Oates. 1988. The location of impurities in Antarctic ice. Ann. Glaciol., 11, 194-197. 